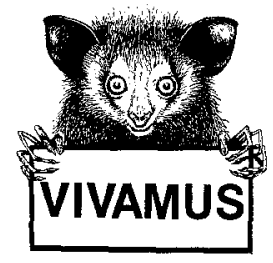

\title{
Demography of Agile Gibbons (Hylobates agilis)
}

\author{
John C. Mitani ${ }^{1,2}$ \\ Received November 17, 1989; revised April 6, 1990
}

Demographic processes and the structure of a population of agile gibbons (Hylobates agilis) were investigated over 6 years in the Gunung Palung Reserve, Indonesia. Estimates of population size, density, and biomass revealed a population whose groups were stable in size and composition. Demographic processes place gibbons at risk, however, to short-term changes in their environment. Patterns of survival, fecundity, mortality, and dispersal combined to produce negative rates of growth. In addition, a top-heavy age-class distribution, with adults forming a large fraction of animals, makes it unlikely that this population could recover rapidly from a decline in numbers. Two behavioral factors, territoriality and monogamy, account for the size and stability of gibbon groups. Monogamy imposes limits on group size, while mating patterns and territoriality decrease the impact of sources of high mortality common in other primate species. These relationships underscore the fundamental importance of behavioral influence on demographic processes and social structure.

KEY WORDS: demography; conservation; behavior; gibbons.

\section{INTRODUCTION}

Demography occupies a pivotal role in current field studies of primates. From a practical standpoint, demographic data provide information needed to evaluate the overall health of primate populations. As threats to these popu-

${ }^{1}$ The Rockefeller University Field Research Center, Tyrrel Road, Millbrook, New York 12545. ${ }^{2}$ Present address: Department of Anthropology, University of Michigan, Ann Arbor, Michigan 48109. 
lations increase, the implementation of effective conservation measures will depend on an understanding of demographic processes and patterns. The theoretical significance of demographic studies is related to the fact that the behavior of animals directly affects population processes and structure. Demographic consequences of behavior thus promise to contribute to an understanding of the factors responsible for the structure of social groups, a central issue of primate behavioral ecology.

Gibbons are territorial, monogamous apes, which range widely over the rain forests of Southeast Asia. Although these animals have been the subjects of numerous field investigations, demographic data are generally limited to a few groups from each population (Leighton, 1987). The principal goal of this paper is to provide information on the demographic structure of a multiple-group population of agile gibbons (Hylobates agilis). Estimates are made of population size, density, biomass, and age-sex composition. In addition, long-term observations permit evaluations of demographic processes, including survival, fecundity, mortality, dispersal, and population growth. These data provide relevant information for conservation and management purposes and insights into the relationships among behavior, demographic processes, and social structure.

\section{METHODS}

\section{Study Site and Animals}

A population of agile gibbons (Hylobates agilis) was monitored for 6 years between 1984 and 1989 at the Cabang Panti research station in the Gunung Palung Nature Reserve, West Kalimantan, Indonesia. Field observations took place for 3 weeks during August-September 1984, 5 months during June-October 1985, 5 months during June-October 1986, 4 months during August-November 1988, and 4 months during April-July 1989. Fieldwork was not conducted in 1987, but information regarding two groups was provided by $C$. Cannon, who made observations in my absence. The $15-\mathrm{km}^{2}$ study site comprised a mosaic of habitats including lowland dipterocarp, peat swamp, and hill dipterocarp forests. A network of trails, measuring over $50 \mathrm{~km}$ and marked at 50-m intervals, covered the study area and facilitated the determination of locations.

Monogamous family groups and solitary floating individuals formed the study population. Observations were made of 28 groups in 1 year, 1986. In the following analyses, most data derive from 10 groups, which were monitored consistently during 4 years (Table I). All of the adults of these groups, with the exception of the animals in one (ST), could be recognized individually. 
Table I. Gibbon Group Size, Population Density, and Biomass $^{a}$

\begin{tabular}{|c|c|c|c|c|c|c|}
\hline Group & 1984 & 1985 & 1986 & 1987 & 1988 & 1989 \\
\hline MT & 3 & 3 & 3 & 4 & 4 & 3 \\
\hline HR & 5 & 5 & 5 & 5 & 5 & 4 \\
\hline PR & 6 & 7 & 7 & & 7 & 6 \\
\hline TB & 5 & 5 & 5 & & 5 & 4 \\
\hline AY & & 4 & 3 & & 4 & 4 \\
\hline DR & & 3 & 3 & & 4 & 3 \\
\hline SI & & 5 & 5 & & 4 & 4 \\
\hline MB & & 4 & 3 & & 3 & 3 \\
\hline DA & & 5 & 5 & & 5 & 5 \\
\hline ST & & 4 & 4 & & 4 & 3 \\
\hline ML & & 5 & 5 & & & \\
\hline HB & & 3 & 3 & & & \\
\hline DP & & & 4 & & & \\
\hline BS & & & 4 & & & \\
\hline TK & & & 3 & & & \\
\hline GP & & & 3 & & & \\
\hline MR & & & 3 & & & \\
\hline LC & & & 3 & & & \\
\hline TR & & & 3 & & & \\
\hline SF & & & 2 & & & \\
\hline UB & & & 4 & & & \\
\hline RS & & & 3 & & & \\
\hline RB & & & 4 & & & \\
\hline KP & & & 2 & & & \\
\hline SP & & & 4 & & & \\
\hline WW & & & 4 & & & \\
\hline KT & & & 4 & & & \\
\hline GI & & & 3 & & & \\
\hline
\end{tabular}

\begin{tabular}{lcccccc}
$\begin{array}{c}\text { Solitaries } \\
\text { Males }\end{array}$ & 0 & 1 & 3 & 0 & 0 & 0 \\
$\begin{array}{c}\text { Females } \\
\text { Density }\end{array}$ & 0 & 0 & 0 & 0 & 1 & 1 \\
$\begin{array}{l}\text { (animals/ } \\
\left.\mathrm{km}^{2}\right)\end{array}$ & 15.6 & 14.9 & & 15.6 & 13.5 \\
$\begin{array}{c}\text { Biomass } \\
\left(\mathrm{kg} / \mathrm{km}^{2}\right)\end{array}$ & 72.2 & 72.6 & & 74.2 & 64.3 \\
\hline
\end{tabular}

${ }^{a}$ The number of individuals in each group is shown. Population density and biomass figures are based on the 10 primary study groups (first 10 listed; MT-ST), which were monitored between 1985 and 1989 .

Age classes of gibbons were assigned by using physical and behavioral characteristics of animals (cf. Leighton, 1987). Animals from birth to 2-2.5 years were classified as infants. Infants were easily recognized since they were still carried by their mothers during travel. Juveniles, between 2 and 4 years of age, were defined by their small size (< one-half of adults) and locomo- 
tion independent of their mothers. Individuals not yet adult size ( $>$ one-half of adults) between 4 and 6 years old were classified as adolescents. Subadults, greater than 6 years old, were similar in size to adults but not yet mated. Mated animals and solitary floating individuals formed the adult age class.

\section{Observational Methods}

Gibbons were censused at least once every 2 months during each study period. Animals were typically located by their loud singing performances and then followed for a variable period until reliable identifications of individuals could be made.

In the field, physical and behavioral features facilitated identification of the ages and sexes of animals (cf. Brockelman and Gittins, 1984; Marshall et al., 1984). Adult male gibbons sported conspicuous white beards and white tufts of hair around their genitalia. In contrast, adult females lacked white beards and were unique among group members in this respect. Mature female and male gibbons were readily distinguished from each other by their sex-specific songs (Mitani, 1987, 1988). Singing behavior also served as a useful cue in identifying other age-sex classes of animals. Subadult males typically engaged in prolonged singing performances during the hours around dawn. These performances were delivered alone or together with their fathers. Subadult females usually contributed to the mated pairs" early morning duetting performances. Subadults delivered "great calls" that did not differ substantially in their acoustic morphology from those of adults. In contrast, the songs of adolescent and juvenile gibbons were recognized in the field as acoustically simple, lower-amplitude version of adults'.

Physical and behavioral cues also aided in identifying individual gibbons. Facial scars and pelage characteristics served as reliable markers of individuals. In addition, several animals in the study population could be recognized individually by idiosyncrasies in their songs (cf. Haimoff and Gittins, 1985).

\section{Population Analyses}

Field observations of animals provided information on population size, density, biomass, group size, births, age-sex compositions of groups, and disappearances. The population size of 10 groups was monitored during 4 years. Two measures of the population's rate of increase were made during three successive time intervals (Caughley, 1977). The population's observed rate of increase, defined as $r$, was calculated from $r=\ln N_{t}-\ln N_{0} / t$, where $N_{0}$ is the population size at the start of observations and $N_{t}$ is the popula- 
Table II. Population Rates of Increase During Three Sample Periods $^{a}$

\begin{tabular}{llcc}
\hline & $1985-1986$ & $1986-1988$ & $1988-1989$ \\
\hline$r$ & $-0.040(17 \mathrm{yr})$ & $0.025(28 \mathrm{yr})$ & $-0.140(5 \mathrm{yr})$ \\
$r_{\mathrm{s}}{ }^{1}$ & $-0.220(3 \mathrm{yr})$ & $-0.050(14 \mathrm{yr})$ & $-0.350(2 \mathrm{yr})$ \\
$r_{\mathrm{s}}{ }^{2}$ & $-0.070(10 \mathrm{yr})$ & $0.004(173 \mathrm{yr})$ & $-0.100(7 \mathrm{yr})$ \\
\hline
\end{tabular}

${ }^{a}$ Numbers in parentheses show the number of years (yr) it would take the population to halve (for $r$ and $r_{\mathrm{s}}$ negative) given the indicated rate of increase. $r_{\mathrm{s}}{ }^{1}$ based on the assumption that all animals in the population that disappeared died. $r_{\mathrm{s}}{ }^{2}$ is based on the assumption that presubadult disappearances were due to mortality, but all subadults dispersed successfully and reproduced.

tion size at the end of observations. Estimates of $r_{\mathrm{S}}$, the rate of increase based on survival and fecundity schedules, were computed for each interval using survivorship and fecundity statistics calculated from each time period. Survivorship was determined during each interval by comparing the number of animals in the 10-group population at each point in time (Caughley, 1977). For purposes of these analyses, the age of reproducing adults was considered to be 15 years. Two extreme estimates of $r_{\mathrm{S}}$ were made to sample the possible range of variation. For one estimate $\left(r_{\mathrm{s}}{ }^{1}\right.$; Table II), I assumed all animals that disappeared died; in a second estimate $\left(r_{\mathrm{s}}{ }^{2}\right.$; Table II), the same assumption was made for presubadult animals, but all subadults were assumed to disperse successfully and reproduce.

The territories of 5 of the 10 primary study groups were well-known. The size of the area covered by these groups' territories was determined by superimposing a grid of 1-ha quadrats over a map of the study site and counting the total number of quadrats used by the animals. This figure was then multiplied by 0.02 to produce an estimate of the total area in square kilometers $(x)$ occupied by the study population. The population density of gibbons was derived by dividing the total number of gibbons in each year by $x$; no corrections for overlapping ranges or changes in territory size were made since the gibbons possessed site-specific, exclusive territories.

Biomass $\left(\mathrm{kg} / \mathrm{km}^{2}\right)$ was computed by dividing the total weight of the 10-group population by population size and multiplying by population density. Population group weight was calculated by using adult body weights from Jungers (1984). Weights of subadults were considered equal to those of adults. Weights of other animals were assumed to be as follows: adolescents, $0.75 \times$ adult body weight; juveniles, $0.50 \times$ adult body weight; and infants, $0.25 \times$ adult body weight.

Births were recorded by noting the presence of new infants in established groups. Using a sample of five females, which gave birth twice during the study period, interbirth intervals were computed by counting the time elapsed between successive observations of infant appearances. Mean fecun- 


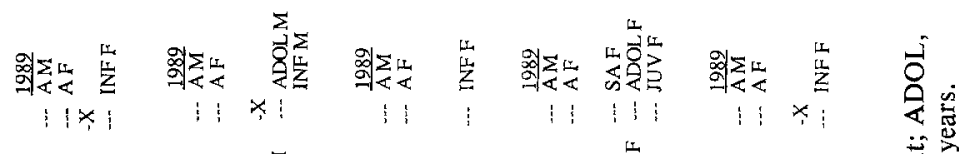

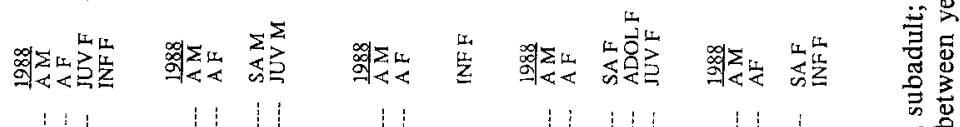

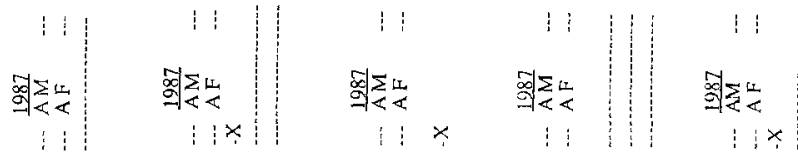

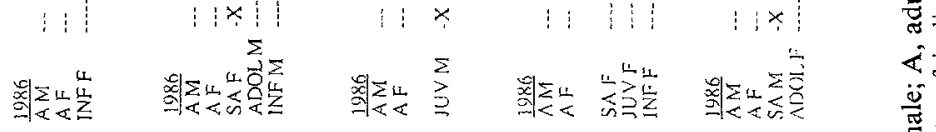

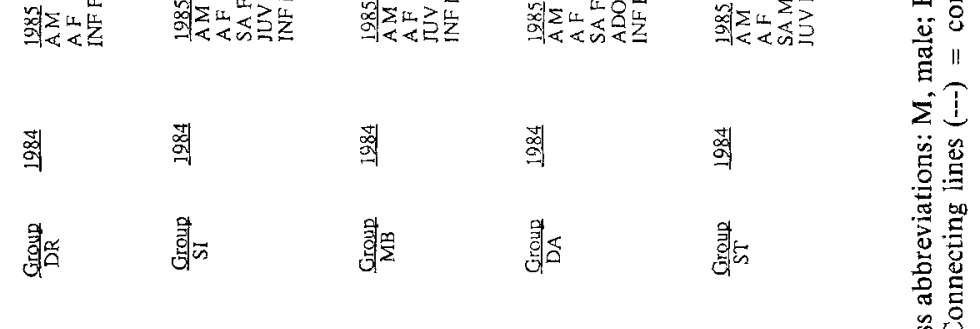

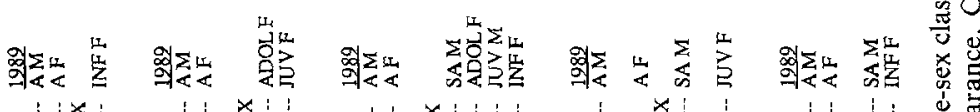

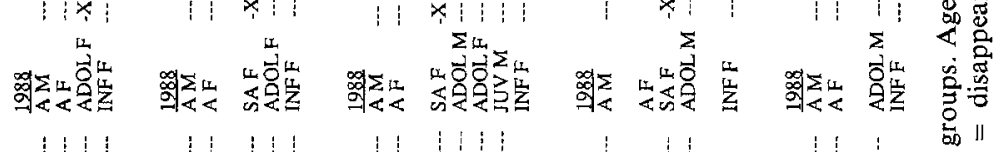

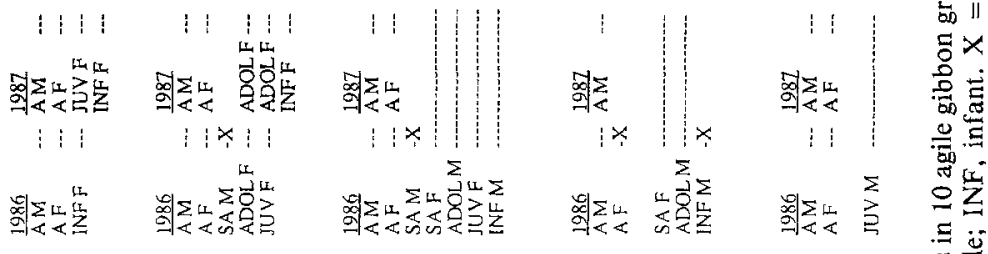

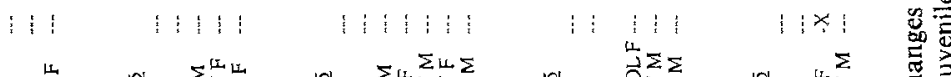

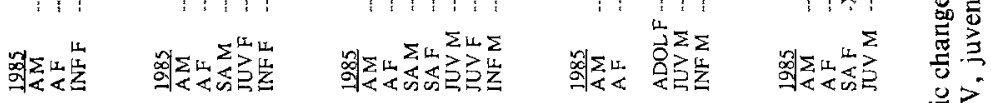

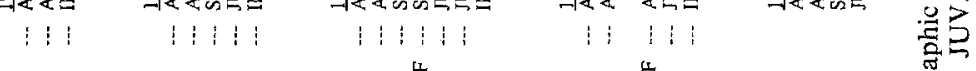

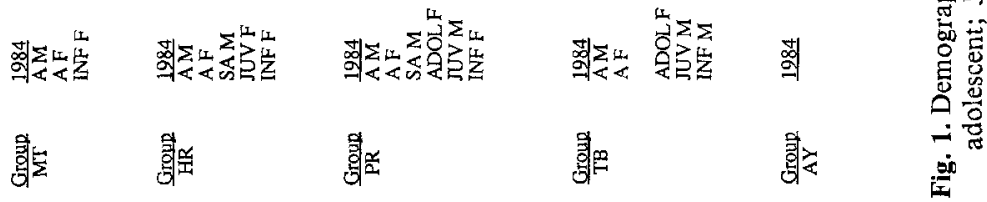


dity over the 6-year observation period was calculated as the average number of female infants born to adults (Caughley, 1977).

Disappearances by animals of different age classes were noted and contributed to information regarding mortality and dispersal. Immature (< subadult) gibbons have been observed only rarely to disperse successfully from their natal groups (Leighton, 1987), and all disappearances of these animals were considered terminal. Disappearances by subadults were attributed to dispersal since all subadults underwent a period of peripheralization from their natal subgroups before disappearing.

\section{RESULTS}

\section{Population Size}

Reliable counts of 10 groups exist for 1985, 1986, 1988, and 1989 (Table I, Fig. 1). During these 4 years, this study population fluctuated between 45 and 39 animals. The population's rate of increase varied between years. Table II shows the rates of increase in the population measured between three sample periods: 1985-1986, 1986-1988, and 1988-1989.

Between 1985 and 1986 the population declined with $r=-0.04$. Given this growth rate, the population would halve every 17 years. During this same period, estimates of the rate of increase $\left(r_{\mathrm{S}}\right)$ based on survivorship and fecundity schedules were much lower, between -0.22 and -0.07 , with halving times of 3 and 10 years, respectively. The population reached its lowest point during the last year due to the disappearance of five subadults, one adolescent and one juvenile, and between 1988 and $1989 r$ and $r_{\mathrm{S}}$ were considerably lower than between 1985 and 1986 (Table II). The population expanded slightly during the 2-year period spanning 1986 and 1988 (Table II). Although the observed rate of increase was positive during this period, one estimate of $r_{\mathrm{S}}$, based on survivorship and fecundity, was negative $\left(r_{\mathrm{S}}{ }^{1}\right.$, Table II).

\section{Population Density and Biomass}

Table I presents changes in the population density and biomass of the gibbon population at Cabang Panti during 4 years. The mean population density over the 4-year period was 14.9 animals $/ \mathrm{km}^{2}(\mathrm{SD}=1.0 ; 95 \%$ confidence interval $=13.3-16.5)$. Biomass varied between 64 and $74 \mathrm{~kg} / \mathrm{km}^{2}(\bar{X}$ $=70.8 ; \mathrm{SD}=4.4 ; 95 \%$ confidence interval $=63.8-77.9)$.

\section{Births, Interbirth Intervals, and Fecundity}

Figure 1 illustrates demographic changes in the 10 primary study groups between 1984 and 1989. During this 6-year period, five females gave birth 
to successive infants, with a mean interbirth interval of 3.2 years $(S D=0.4)$. This figure is a minimum, which is likely to be an underestimate insofar as several females in the study population gave birth only once. Based on the reproductive histories of 11 females (Fig. 1), the mean birth rate of the population measured over the 6-year study period was 0.32 infant/adult female/year. Female births outnumbered those of males, and the mean fecundity, 0.25 female infant/adult female/year, was greater than half of the mean birth rate. The sex ratio at birth, although biased toward females, was not significantly different from unity (two-tailed binomial test, $P>0.05$; Fig. 1).

\section{Group Size}

Table I shows the sizes of each gibbon group over the 6-year observation period. During each year, group sizes averaged approximately four animals. The number of groups for whom observations are available, however, varies between years. To examine the relative stability of groups over time, I compared the variability in sizes of the 10 groups that were regu-

1985

1986

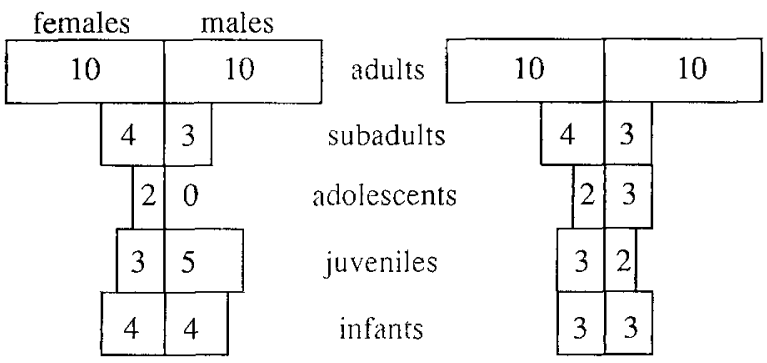

1988

1989
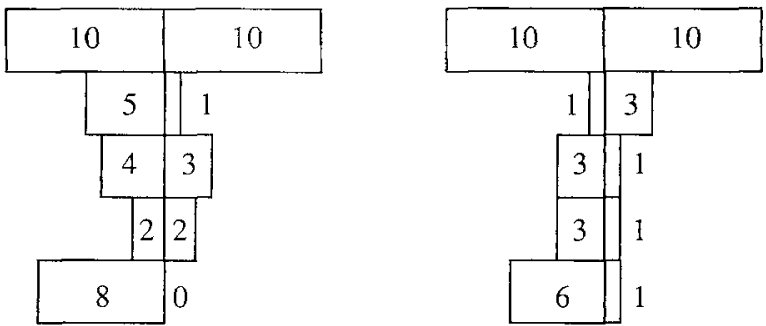

Fig. 2. Age-sex class pyramids of the Cabang Panti agile gibbon population in each of 4 years. 
larly monitored during $1985,1986,1988$, and 1989 . These groups showed few changes in composition, and the mean within-group size variance $\left(s^{2}=\right.$ 0.23 ) was significantly smaller than the population's total variance in group sizes $\left(s^{2}=1.29 ; F_{39,9}=5.55, P<0.01\right)$.

\section{Age-Sex Compositions}

Figure 2 shows age-sex class pyramids for the study population in each of 4 years. Age classes did not contribute equally to the total population in each year $\left(\chi^{2}, P<0.001\right.$ for each sample), but age-class contributions did not differ among years $\left(\chi^{2}, P>0.90\right)$. Within years, adults consistently composed approximately half of the population, ranging from $51 \%$ in 1989 to $44 \%$ in 1985 and 1986 . Subadults formed a small fraction of the total population (10\%) in 1989, while adolescents contributed equally small portions in 1985 and 1989. Juveniles and infants combined as a group to form more than $25 \%$ of the population in each census year.

Females outnumbered males in every census year, with the populationwide sex ratio (females:males) ranging from 1.11 in 1984 to 1.67 in 1988. Sex ratios, however, did not differ significantly from unity in any year (twotailed binomial test, $P>0.20$ for each yearly sample).

\section{Mortality and Dispersal}

The 10 groups that were monitored regularly contributed to information regarding mortality and dispersal (Fig. 1). The ages and sexes of individuals which disappeared during the study period are presented in Table III. Five of 28 immature (<subadult age) animals disappeared over 6 years. Assuming that all of these disappearances were due to unobserved deaths, this corresponds to a mortality rate of $18 \%$. Disappearances and presumed mor-

Table III. Disappearances of Gibbons of Different Age-Sex Classes from 10 Groups over 6 Years

\begin{tabular}{lcc}
\hline & \multicolumn{2}{c}{ Sex } \\
\cline { 2 - 3 } Age class & Male & Female \\
\hline Adult & 0 & 1 \\
Subadult & 4 & 7 \\
Adolescent & 0 & 1 \\
Juvenile & 2 & 1 \\
Infant & 1 & 0 \\
$\quad$ Total & 7 & 10 \\
\hline
\end{tabular}


tality were not equally distributed among immature age classes. Of the five animals which disappeared, one was an infant, three were juveniles, and one was an adolescent. No sex bias in disappearances existed (Table III).

In contrast to the relatively low rate of disappearance of immature animals, virtually all subadults disappeared (11 of 13 animals, $85 \%$; Table III). Since all of these animals were peripheralized from their natal groups before disappearing, they are considered to have dispersed. The ultimate fates of these individuals remain unknown, however. It was not possible to track any of these animals to ascertain whether they established a territory and mated successfully or died during the dispersal process.

Only one adult, a mated female, disappeared. This animal, with matted hair and a quavering voice, appeared to be in extremely poor condition, and for this reason she was thought to have died.

\section{DISCUSSION}

\section{Implications for Conservation}

Gibbons are widely distributed throughout the remaining rain forests of Southeast Asia (Chivers, 1986). If given a suitable habitat within these

Table IV. Population Densities of Gibbons and Sympatric Primate Species

\begin{tabular}{llcl}
\hline Study site & Species & $\begin{array}{c}\text { Population density } \\
\text { (animals } / \mathrm{km}^{2} \text { ) }\end{array}$ & Reference \\
\hline G. Leuser & Hylobates syndactylus & 15 & Rijksen (1978) \\
& Hylobates lar & 11 & \\
& Pongo pygmaeus & 5 & \\
& Presbytis thomasi & 27 & \\
& Macaca fascicularis & 48 & \\
Kutai & M. nemestrina & 19 & Rodman (1977) \\
& Hylobates muelleri & 15 & \\
& P. pygmaeus & 4 & \\
& Presbytis hosei & 20 & \\
Krau & M. fascicularis & 6 & \\
& M. nemestrina & 6 & \\
& H. syndactylus & 13 & Chivers (1980) \\
& H. lar & 13 & \\
& Presbytis obscura & 31 & \\
Siberut & Presbytis melalophos & 74 & \\
Hollongapar & M. fascicularis & 39 & \\
Bangladesh & Hylobates klossi & 1 & Tenaza (1975) \\
Tripura & H. hoolock & 30 & Tilson (1979) \\
Java & H. hoolock & 14 & Gittins (1984) \\
\hline
\end{tabular}


forests, these animals exist at relatively high population densities. The population density of gibbons at Cabang Panti, ranging between 14 and 16 animals $/ \mathrm{km}^{2}$, is comparable to those of other gibbon species, and exceeds estimates of some sympatric primate populations (Table IV). Despite living at such high densities, the Cabang Panti gibbons are vulnerable due to their peculiar life history characteristics.

The minimum interbirth interval of 3.2 years from this study approximates estimates from other populations of gibbons and is significantly higher than that of most monkeys and prosimians (Smuts et al., 1987). These long reproductive cycles combined with patterns of survivorship to produce negative rates of population increase during two samples between 1985 and 1989 $\left(r_{\mathrm{s}}\right.$ values in Table II). These figures indicate that the population is capable of crashing to one-half its original size in as little as 2 years. While this alarming estimate is based on an unusual period during which five subadult animals dispersed, even under the most favorable conditions of growth (1986-1988), the rate of increase, based on survivorship and fecundity, was vanishingly small or negative (Table II).

Two caveats must be added. First, one projected estimate of growth $\left(r_{\mathrm{s}}{ }^{1}\right)$ posited a worst-case scenario in which all dispersing individuals were assumed to have died. The validity of this assumption may be questionable, and if wrong, the negative values of $r_{\mathrm{S}}$ presented here are exaggerated and should be interpreted within the context provided by the alternative population growth estimate $\left(r_{\mathrm{s}}{ }^{2}\right.$, Table II). Second, the population rates of increase in this study, based on only 10 groups, are subject to small sample size biases and may not be representative. This observation emphasizes the limitations of the present study and the need for longer records of a larger population.

With these caveats in mind, the ability of the Cabang Panti gibbon population to recover from negative growth can still be assessed by examining other demographic features. The age-sex composition of the population provides an indicator of the potential for expansion. The patterns of reproduction, mortality, and dispersal in gibbons produced a top-heavy age-class pyramid (Fig. 2), with adults contributing a disproportionate share of animals to the total population. Unfortunately, this age distribution, with few animals under reproductive age, is not conducive to population growth (Caughley, 1977). As a result, the gibbons at Cabang Panti would recover from a decline in numbers with difficulty.

In summary, the lesson for conservation biologists contained in these demographic parameters is sobering. As much of the habitat occupied by gibbons continues to be destroyed (Chivers, 1986), the life-history characteristics of gibbons will conspire against conservation measures taken to protect them. 


\section{Behavioral Influences on Demographic Processes and Social Structure}

Altmann and Altmann (1979) noted the ways in which the demographic structure of a population affects the behavior of animals. While demographic constraints on behavior undoubtedly exist, they may obscure the fundamental importance that behavior itself has on influencing demographic processes and structure (cf. Fig. 1 of Altmann and Altmann, 1979). Through their effects on group size and the processes of mortality and dispersal, behavioral factors play a critical role in shaping the structure of gibbon populations.

With the possible exception of the white-cheeked gibbon, Hylobates concolor (Haimoff et al., 1986), all gibbon species are monogamous and territorial (Leighton, 1987). Territorial monogamy is a rare social system, found in less than 5\% of all mammal species (Kleiman, 1977), and the unusual demographic structure displayed by gibbons can be related to aspects of their spacing and mating behavior. Long-term observations of 10 groups revealed a remarkable stability in group size and composition over time. The pair bonds formed by long-lived adults undoubtedly contribute to this stability, as monogamy imposes severe limits on the size and structure of groups.

The unusually stable population structure found in this study was also a function of one significant demographic process: low rates of mortality in the youngest age classes. This demographic process was in turn affected by the behavior of gibbons. The pattern of mortality described here for gibbons differs markedly from that reported in other primate species. In contrast to the low rates of presubadult mortality shown by the gibbons at Cabang Panti, high rates of mortality, ranging up to $60 \%$, have been documented in populations of monkeys and apes (Dunbar, 1987). Ecological factors, such as food shortage and predation, have been suggested as primary causes of infant mortality in some populations of monkeys (Altmann et al., 1977; Cheney et al., 1981; Dittus, 1975). In contrast, high infant mortality in other monkeys and apes has been attributed to social causes, including infanticide and aggression between females (Glander, 1980; Goodall, 1983; Hiraiwa-Hasegawa et al., 1984; Watts, 1988). Since territorality limits food competitors and monogamy provides few opportunities for infanticide, the behavior of gibbons may act as a buffer against some of the common ecological and social pressures that cause high mortality in other primate species.

While acting to decrease mortality in some cases, the behavior of gibbons may virtually guarantee death to the majority of subadults. Turnover in the study population was due primarily to dispersal by subadult animals. Although the fates of all subadults which disappeared during this study are unknown, it is unlikely that many of these animals survived to reproduce since few floaters were ever observed. Successful dispersal is probably difficult 
for two reasons related to territoriality and monogamy. First, floating subadults receive severe aggression from mated territorial adults (Tenaza, 1975; Mitani, 1988). Second, habitats in which gibbons are normally found, such as the Cabang Panti site, are saturated with gibbon territories; few vacancies occur due to the mated status and relatively long life spans of adults. Given a shortage of suitable habitat in a socially hostile environment, it is reasonable to assume that most floating subadult animals die after leaving their natal groups. Longitudinal field observations of dispersing individuals are necessary to evaluate this proposal, as well as other demographic consequences of gibbon behavior.

\section{ACKNOWLEDGMENTS}

Research was supported by grants from the National Geographic Society, the L. S. B. Leakey Foundation, the National Science Foundation (BSN-8805275), the Harry Frank Guggenheim Foundation, and a NRSA fellowship from the NIH (F32 NS07670). Fieldwork in Indonesia was sponsored by the Indonesian Institute of Sciences, the Indonesian Directorate General of Forest Protection and Nature Conservation, and the Indonesian National Biological Institute. I thank C. Darsono for providing logistic aid in the field; C. Cannon for supplying observations in my absence; G. Grether for help with preparing the manuscript; and W. Bleisch, G. Grether, S. Harcourt, P. Marler, R. Palombit, and K. Strier for comments and discussion.

\section{REFERENCES}

Altmann, J., Altmann, S., Hausfater, G., and McCuskey, S. (1977). Life history of yellow baboons: Physical development, reproductive parameters and infant mortality Primates 18: 315-330.

Altmann, S., and Altmann, J. (1979). Demographic constraints on behavior and social organization. In Bernstein, I., and Smith, E. (eds.), Primate Ecology and Human Origins, Garland Press, New York, pp. 47-63.

Brockelman, W., and Gittins, S. P. (1984). Natural hybridization in the Hylobates lar species group: Implications for speciation in gibbons. In Preuschoft, H., Chivers, D., Brockelman, W., and Creel, N. (eds.), The Lesser Apes, Edinburgh University Press, Edinburgh, pp. 498-532.

Caughley, G. (1977). Analysis of Vertebrate Populations, John Wiley, New York.

Cheney, D., Lee, P., and Seyfarth, R. (1981). Behavioral correlates of non-random mortality among free-ranging vervet monkeys. Behav. Ecol. Sociobiol. 9: 153-161.

Chivers, D. (1980). Malayan Forest Primates, Plenum, New York.

Chivers, D. (1986). Southeast Asian primates. In Benirschke, K. (ed.), Primates: The Road to Self-Sustaining Populations. Springer-Verlag, Berlin, pp. 125-151.

Dittus, W. (1975). Population dynamics of the toque macaque, Macaca sinica. In Tuttle, R. H. (ed.), Sociology and Psychology of Primates, Mouton, The Hague, pp. 125-151. 
Dunbar, R. (1987). Reproduction and demography. In Smuts, B., Cheney, D., Seyfarth, R., Wrangham, R., and Struhsaker, T. (eds.), Primate Societies, University of Chicago Press, Chicago, pp. 240-249.

Gittins, S. P. (1984). The distribution and status of the hoolock gibbon in Bangladesh. In Preuschoft, H., Chivers, D., Borckelman, W., and Creel, N. (eds.), The Lesser Apes, Edinburgh University Press, Edinburgh, pp. 13-15.

Glander, K. (1980). Reproduction and population growth in free-ranging mantled howler monkeys. Am. J. Phys. Anthropol. 53: 25-36.

Goodall, J. (1983). Population dynamics during a 15 year period in one community of freeliving chimpanzees in the Gombe National Park, Tanzania. Z. Tierpsychol. 61: 1-60.

Haimoff, E., and Gittins, S. P. (1987). Individuality in the songs of wild agile gibbons ( $\mathrm{Hylo}-$ bates agilis) of Peninsular Malayasia. Am. J. Primatol. 8: 239-247.

Haimoff, E., Yang, X.-J., He, S.-J., and Chen, N. (1986). Census and survey of wild backcrested gibbons (Hylobates concolor concolor) in Yunnan Province, People's Republic of China. Folia Primatol. 46: 205-214.

Hiraiwa-Hasegawa, M., Hasegawa, T., and Nishida, T. (1984). Demographic study of a largesize unit-group of chimpanzees in the Mahale Mountains, Tanzania: A preliminary report. Primates 25: 401-413.

Jungers, W. (1984). Scaling of the hominoid locomotor skeleton with special reference to the lesser apes. In Preuschoft, H., Chivers, D., Brockelman W., and Creel, N. (eds.), The Lesser Apes, Edinburgh University Press, Edinburgh, pp. 146-169.

Kapeller, M. (1984). The gibbon in Java. In Preuschoft, H., Chivers, D., Brockelman, W., and Creel, N. (eds.), The Lesser Apes, Edinburgh University Press, Edinburgh, pp. 19-31.

Kleiman, D. (1977). Monogamy in mammals. Q. Rev. Biol. 52: 39-69.

Leighton, D. (1987). Gibbons: Territoriality and monogamy. In Smuts, B., Cheney, D., Seyfarth, R., Wrangham, R., and Struhsaker, T. (eds.), Primate Societies, University of Chicago Press, Chicago, pp. 135-145.

Marshall, J., Sugardjito, J., and Markaya, M. (1984). Gibbons of the lar group: Relationships based on voice. In Preuschoft, H., Chivers, D., Brockelman, W., and Creel, N. (eds.), The Lesser Apes, Edinburgh University Press, Edinburgh, pp. 533-541.

Mitani, J. (1987). Territoriality and monogamy among agile gibbons (Hylobates agilis). Behav. Ecol. Sociobiol. 20: 265-269.

Mitani, J. (1988). Male gibbon (Hylobates agilis) singing behavior: Natural history, song variations and function. Ethology 79: 177-194.

Murkherjee, R. P. (1982). Survey of non-human primates of Tripura, India. J. Zool. Soc. India 34: 70-81.

Rijksen, H. (1978). A Field Study on Sumatran Orangutans (Pongo pygmaeus abelli Lesson 1827), H. Veenman and Zonen B.V., Wageningen.

Rodman, P. (1978). Diets, densities and distributions of Bornean primates. In Montgomery, G. (ed.), The Ecology of Arboreal Folivores, Smithsonian Institution Press, Washington, D.C., pp. $465-478$.

Smuts, B., Cheney, D., Seyfarth, R., Wrangham, R., and Struhsaker, T. (1987). Primate Societies, University of Chicago Press, Chicago.

Tenaza, R. (1975). Territory and monogamy among Kloss' gibbons (Hylobates klossi) in Siberut Island, Indonesia. Folia Primatol. 24: 60-80.

Tilson, R. (1979). Behaviour of hoolock gibbon (Hylobates hoolock) during different seasons in Assam, India. J. Bombay Nat. Hist. Soc, 76: 1-16.

Watts, D. (1989). Infanticide in mountain gorillas: New cases and a reconsideration of the evidence. Ethology 81: 1-18. 